\title{
AS POSSIBILIDADES DA LITERATURA INFANTIL/JUVENIL NO PROCESSO DE APRENDIZAGEM HISTÓRICA
}

\author{
THE POSSIBILITIES OF CHILDREN'S LITERATURE IN THE PROCESS OF \\ LEARNING HISTORY
}

Ana Beatriz Accorsi Thomson ${ }^{1}$

\begin{abstract}
RESUMO: Essa pesquisa tem como objetivo geral estabelecer considerações acerca da utilização dos paradidáticos no ensino de história e analisar como os professores se relacionam e entendem tais materiais. Nesse sentido, buscamos inicialmente nesse artigo investigar o contexto de surgimento da literatura infantil/juvenil e dos materiais paradidáticos voltados ao ensino de história. Buscamos analisar também as tendências mais atuais dos materiais literários voltados ao público jovem, verificando as possibilidades de articulação com um ensino de história mais significativo e preocupado com a alteridade. Consideramos importante verificar a hipótese de que a utilização desse tipo de material possa expandir os conteúdos que normalmente são abordados pelos professores no ensino de história, podendo representar também um incentivo à formação do aluno-leitor. Assim, concordamos com as propostas teóricometodológicas do campo da Educação Histórica, que têm buscado analisar e compreender as diversas práticas em sala aula, as relações entre professores e alunos, a construção do conhecimento histórico, das narrativas e, também, como os materiais didáticos e paradidáticos se articulam ao processo de aprendizagem.
\end{abstract}

Palavras-chave: Literatura. Ensino de história. Paradidáticos.

\begin{abstract}
This research aims to establish general considerations about the use of paradidadics in the process of history teaching and analyze how teachers understand this kind of materials. Thus, we seek initially in this article to investigate the emergence of the children's literature and paradidadics used at history teaching. We also will analyze the most current trends in literature materials aimed at young audiences, checking the possibilities of articulation with a more meaningful history education and concerned with otherness. We consider also important to check the hypothesis that the use of such material can expand the contents that are usually addressed by teachers in history teaching, can also represent an incentive to the formation of the studentreader. Thus, we agree with the theoretical and methodological proposals from the field of History Education, who have sought to analyze and understand the various practices in classroom, relations between teachers and students, the construction of historical knowledge, narratives and also how textbooks and paradidatics articulate in the learning process.
\end{abstract}

Keywords: Literature. History Teaching. Paradidadics.

\footnotetext{
${ }^{1}$ Mestre em História Social pela Universidade Estadual de Londrina.
} 
[...] trabalhar com a literatura infantil representa, simultaneamente, contribuir para a formação integral da criança e inseri-la na alteridade, isto é, no contato com o que é diferente dela [...].

(COSTA, 2007, p. 33).

\section{Introdução}

Acreditamos ser cada vez mais necessária a reflexão acerca das práticas de leitura entre os jovens na atualidade. Segundo Coelho (2000), o contexto cultural de transformações tecnológicas e comunicativas, estabelecido no final do século $X X$, vem influenciando debates $e$ reformulações no âmbito da Literatura voltada ao público adolescente. A autora aponta uma das inquietações vivenciadas na atualidade: qual seria o lugar da literatura em um mundo cada vez mais tecnológico?

Concordamos com a resposta dada por essa mesma autora à sua própria inquietação. Segundo ela, "[...] a literatura, e em especial a infantil, tem uma tarefa fundamental a cumprir nesta sociedade em transformação: a de servir como agente de formação, seja no espontâneo convívio leitor/livro, seja no diálogo leitor/texto estimulado pela escola" (COELHO, 2000, p. 15).

Assim, para que possamos compreender como vem se estruturando o meio literário voltado aos jovens e quais os papeis que ele tem assumido na atualidade, buscaremos verificar brevemente como se deu o surgimento desse tipo de recurso no contexto brasileiro. Foi principalmente a partir da década de 1980 que o mercado literário voltado ao público jovem passou a se expandir em larga escala. Nessa época, já existiam as chamadas obras "pioneiras", como aquelas de Monteiro Lobato, por exemplo. No entanto, foi no final do século XX que o campo realmente se expandiu massivamente.

A partir de meados dos anos 80 , a produção de Literatura Infantil/Juvenil 'explode' no mercado editorial, tornando-se quase impossível, ao analista, o registro global das centenas de títulos publicados e o crescente número de novos escritores e ilustradores que surgem no rastro dos pioneiros. (COELHO, 2010, p. 287). 
Mas afinal, como são caracterizadas essas obras literárias voltadas ao público jovem, que têm surgido nos últimos anos? Com a expansão da produção desses materiais, foi necessário estabelecer algumas vertentes principais de caracterização. Coelho (2010) define as atuais tendências da literatura infantil/juvenil em três categorias principais. A primeira categoria, chamada Realista, é formada por obras que buscam retratar o cotidiano típico de uma criança, costumes, pequenos mistérios e aventuras, problemas sociais e reflexões psicológicas. A segunda categoria, intitulada Fantástica, envolve o universo do imaginário e da fantasia. Já a terceira categoria é chamada Híbrida, pois parte de um contexto considerado realista e incorpora elementos do fantástico também.

É evidente que, ao estabelecer essas classificações, a autora não pretende engessar e propor uma divisão única entre as obras, mas apenas delimitar e, de certa forma, mapear as tendências atuais desse universo literário infantil/juvenil.

Vista em conjunto, a atual produção de Literatura destinada a crianças e jovens, entre nós, apresenta uma crescente diversidade de opções temáticas e estilísticas, sintonizadas com a multiplicidade de visões de mundo que se superpõem no emaranhado da 'aldeia global' em que vivemos. (COELHO, 2010, p. 289).

\section{Os paradidáticos "clássicos"}

Dentro desse campo de produção de obras literárias voltadas aos jovens, surgiram também aqueles materiais considerados paradidáticos "clássicos" - que, além estabelecerem relações diretas com a escola e com o processo de aprendizagem, foram produzidos especificamente para esse fim. Segundo Laguna (2001), esses materiais surgiram a partir de debates a respeito das práticas de leitura dos alunos.

Os livros paradidáticos nasceram das discussões sobre a necessidade de autores brasileiros produzirem para crianças e jovens buscando formar, através deles, o desejo, o gosto e o prazer de ler. As editoras passaram a investir em textos alternativos, com temas e linguagem mais acessíveis, que 
serviriam para introduzir o aluno no universo da leitura e prepará-lo para obras mais complexas [...]. (LAGUNA, 2001, p. 48).

Reconhecemos, portanto, que o material paradidático apresenta uma linguagem mais acessível aos alunos, pois já foi produzido com o propósito de ser utilizado para uma faixa etária direcionada. Gatti Junior (2004) traz alguns depoimentos de professores a respeito da utilização desse tipo de material em sala de aula. Um desses professores afirma que: "enquanto o livro didático tinha a preocupação de, por exemplo, dar uma e única versão de um acontecimento, esses textos [paradidáticos] podem introduzir polêmicas" (NEVES apud GATTI JUNIOR, 2004, p. 210).

Nesse sentido, de acordo com Zamboni (1991), os materiais paradidáticos na forma de uma "nova cultura livresca" teriam surgido com a "[...] finalidade de complementar o livro didático, subsidiar o trabalho docente e oferecer ao professor e aos alunos novas abordagens a respeito dos temas estudados e/ou propor outros" (ZAMBONI, 1991, p. 2).

A presença de materiais diversificados e complementares ao livro didático no ensino foi ampliada principalmente devido ao anseio de grupos de professores que desejavam inovar em suas práticas (ZAMBONI, 1991). Criou-se, então, uma demanda para os materiais paradidáticos voltados ao ensino, com o objetivo de dar suporte ao uso do livro didático como fascículos, revistas, textos literários, livros temáticos etc. Inclusive, de acordo com Fonseca (2003, p. 54), muitos dos materiais paradidáticos "[...] tornaram-se um novo campo para a publicação dos trabalhos acadêmicos". A autora inclui esses materiais de "diferentes tipos e enfoques" no movimento de renovação pelo qual passou o ensino de história na década de 1980, que foi acompanhado pelas novidades que apontavam no mercado editorial.

As editoras têm organizado persistentes esquemas visando expandir o mercado consumidor do "paradidático". O incremento mercadológico ocorre por meio de mudanças editoriais, abrangendo aspectos formais e de conteúdo das publicações, em tudo quanto possa atrair o público escolar. (ZAMBONI, 1991, p. 2).

Nesse sentido, devemos procurar compreender o surgimento dos paradidáticos também dentro do contexto mercadológico e editorial, pois 
compreende-se que "[...] os paradidáticos não são tão inocentes, pois sua tessitura é montada com o objetivo de consumo imediato e massivo, semelhante a qualquer tipo de mercadoria vendável" (ZAMBONI, 1991, p. 4,5). Dessa forma, Zamboni (1991) afirma que a educação, no final do século $X X$, passou a abarcar também o setor privado e passou a ser concebida como um "investimento comercial". Ainda segundo a autora, a demanda cada vez mais crescente da ampliação da escolaridade fez com que o Estado não desse mais conta de atender a toda a sociedade e a educação passou a ser considerada uma "mercadoria cultural de massa". Nesse sentido, visando preencher esse espaço que só vinha se ampliando, Zamboni (1991) afirma que as editoras ligadas ao mercado educacional passaram a pensar em alternativas além dos livros didáticos e a partir desse "flanco aberto" investiram na produção dos paradidáticos, que segundo a autora se configuraram como o "novo filão lucrativo".

A denominação paradidático, em catálogos editoriais, apareceu no final da década de 1970. Foi lançada numa política de "marketing" com finalidade comercial por Giro Takashi, que na época trabalhava para a Editora Ática. (ZAMBONI, 1991, p. 11).

Outro fator relevante a ser considerado também é que durante a década de 1980 houve uma crise editorial no Brasil, estimulada pelos altos índices inflacionários. Isso fez com que algumas editoras vendessem até $60 \%$ a menos de um ano para o outro, como exemplifica Zamboni (1991, p. 10). Nesse contexto, os livros com conteúdos didáticos e voltados aos estudantes se mantiveram como esperança e "retaguarda" econômica de muitas editoras.

O filão de ouro para o comércio do livro desloca-se para a juventude. Os editores investem em livros didáticos, literatura infanto-juvenil e agora nos denominados paradidáticos, que começam a entrar fortemente no mercado desde a década de 1980. (ZAMBONI, 1991, p. 11).

Assim, nas últimas décadas do século $X X$ esse tipo específico de material passou a se apresentar como uma rentável alternativa às editoras, configurando também uma nova forma de encararmos o ensino de história, afinal: 
[...] a ampliação do mercado de paradidáticos nos [leva] a concluir que as empresas editoriais tornaram-se, nas últimas duas décadas, agentes poderosos na definição de o que ensinar em história e como ensiná-la na escola fundamental. (FONSECA, 2003, p. 56).

Zamboni (1991) afirma que esses recursos passaram a ser considerados por muitos como a "[...] panaceia de todos os problemas do ensino" (ZAMBONI, 1991, p. 47). No entanto, segundo a autora, muitos deles inovaram apenas no aspecto da linguagem e nas novas formas de apresentação estética, pois seu conteúdo continuava tradicional e os níveis de recortes temáticos também continuavam os mesmos daqueles materiais institucionalizados.

Essa autora realizou uma análise de livros paradidáticos voltados ao público do Ensino Fundamental, publicados principalmente durante a década de 1980. Em seu trabalho ela mapeou os principais paradidáticos do mercado, segundo cada editora e coleção. Ela verificou três coleções em particular: $A$ História em Documentos (Editora Atual), Redescobrindo o Brasil (Editora Brasiliense) e O Cotidiano da História (Editora Ática). Primeiramente, ela verificou as inovações nos formatos e, depois, buscou sistematizar as inovações "conteudísticas". Alguns fatores foram priorizados na análise como: apresentação gráfica, jogos de cores, tipo de letras, ilustrações, vocabulário, papel, páginas, linguagem, recursos narrativos, apresentação da história em quadrinhos, da narrativa ficcional, emprego de documentos, contexto social, sujeitos históricos, relações sociais.

A autora em sua pesquisa pretendeu ainda analisar como se expressava a dinâmica do poder nos materiais. Os níveis de manifestação de poder que foram analisados por Zamboni (1991) são: a organização política (instituições, leis, Igreja, nobreza, etc.) e a interação social (dia a dia, diálogos, posturas, etc.).

Após a análise, Zamboni (1991) concluiu que a relação entre paradidático e inovação pedagógica não se concretizava em termos reais, pois nem sempre esses materiais atendiam aos novos recortes temáticos, ao desenvolvimento de um pensamento crítico, à interpretação de fontes 
históricas e ao questionamento de algumas visões tradicionais da historiografia.

Portanto, o emprego da forma isolada, por mais inovadora que seja, impossibilita o alcance de inovações que apontem para a transformação, que somente será alcançada com mudanças substanciais nas abordagens do conteúdo proposto. $\mathrm{E}$ isto, como acreditamos ter explicitado, não ocorreu, pois, no final a história veiculada continuou sendo aquela exaltadora de heróis, excludente das minorias, reforçadora dos laços de dominação. (ZAMBONI, 1991, p. 200).

Para que a utilização desses materiais pudesse ser realmente significativa, segundo Zamboni (1991), eles deveriam ser agregados a uma abordagem consciente por parte do professor.

Os professores, na procura do novo, buscam nos filmes, nas revistas, nos jornais, recursos que possam lançar mão para inovar em sua prática docente. Entretanto, a sua precária formação, acrescida pela falta de informações a respeito das diferentes linguagens, impede-os de explorar de modo satisfatório todas as possíveis dimensões existentes nestes veículos de comunicação. (ZAMBONI, 1991, p. 76, 77).

\section{As obras literárias vistas como paradidáticos}

Ao consideramos nessa pesquisa os materiais paradidáticos como aqueles que pretendem estabelecer relações diretas com a escola e com o processo de aprendizagem, englobamos também as obras literárias infantil/juvenil de forma geral (e não apenas aquelas produzidas especificamente para serem utilizadas na escola). Como esses materiais podem exercer o papel de "agentes de formação"?

Em primeiro lugar, é necessário compreender que as obras literárias são formadas por determinada representação da realidade. Mesmo que algumas apresentem temas fantásticos, por exemplo, elas são baseadas em certo conjunto de valores e ideias que fazem parte do mundo vivido e representam o universo do qual o jovem faz parte.

Considerada enquanto criação na linguagem, a literatura tem por natureza uma profunda característica social. A linguagem 
pressupõe sempre o contato e a interação entre o criador e produtor do texto e os receptores. Além dessa natureza linguística, a literatura trata de assuntos e temas humanos, isto é, que têm relação com a vida humana (sentimentos, afetos, temores, desejos, vivências), mesmo que apresente personagens sob forma de animais ou objetos, pois eles representam sempre a compreensão do ser humano sobre a realidade. (COSTA, 2007, p. 23).

Assim, compreendemos que a leitura de uma obra literária não se mostra como a simples absorção de uma mensagem ou experiência simplesmente estética, mas sim uma "convivência particular com o mundo criado através do imaginário" (ZILBERMAN, 1985, p. 24). Concordamos, portanto, com De Certeau (1998, p. 266) que "[...] o texto só tem sentido graças a seus leitores; muda com eles; ordena-se conforme códigos de percepção que lhe escapam. Torna-se texto somente na relação à exterioridade do leitor $[\ldots] "$. . De acordo com esse autor,

[Pesquisas] mostram que a criança escolarizada aprende a ler paralelamente à sua aprendizagem da decifração e não graças a ela: ler o sentido e decifrar as letras correspondem a duas atividades diversas, mesmo que se cruzem. Noutras palavras, somente uma memória cultural adquirida de ouvido, por tradição oral, permite e enriquece aos poucos as estratégias de interrogação semântica cujas expectativas a decifração de um escrito afina, precisa ou corrige. Desde a leitura da criança até a do cientista, ela é precedida e possibilitada pela comunicação oral, inumerável "autoridade" que os textos não citam quase nunca. (DE CERTEAU, 1998, p. 263).

Ou seja, a leitura se configura como um processo de intercâmbio entre as experiências vividas pelo leitor com aquele universo simbólico presente na arte literária. Nesse sentido, a obra literária no universo infantil/juvenil "não se reduz a um determinado conteúdo reificado, mas depende da assimilação individual da realidade que recria" (ZILBERMAN, 1985, p. 24).

Da mesma forma, toda leitura que, conscientemente ou inconscientemente, se faça em sintonia com a essencialidade do texto lido, resultara na formação de determinada consciência de mundo no espírito do leitor; resultará na representação de determinada realidade ou valores que tomam corpo em sua mente. Daí se deduz o poder de fecundação e de propagação de ideias, padrões ou valores que é inerente ao fenômeno literário, e que através dos tempos 
tem servido à humanidade engajada no infindável processo de evolução que a faz avançar sempre e sempre.... (COELHO, 2000 , p. 50).

Dessa maneira, entendemos que muito mais do que uma função pedagógica de compreensão "conteudística" as obras literárias para os jovens constituem uma possibilidade para a formação do pensamento crítico e da interpretação da realidade em que vivem. Ao se inspirar em elementos do real e apresentar uma característica dita social, evocando ideias e valores próximos aos leitores, a literatura possibilita o desenvolvimento da capacidade de compreensão de mundo.

Como procede a literatura? Ela sintetiza, por meio dos recursos da ficção, uma realidade, que tem amplos pontos de contato com o que o leitor vive cotidianamente. Assim, por mais exacerbada que seja a fantasia do escritor ou mais distante e diferentes as circunstâncias de espaço e tempo dentro das quais uma obra é concebida, o sintoma de sua sobrevivência é o fato de que ela continua a se comunicar com o destinatário atual, porque ainda fala de seu mundo, com suas dificuldades e soluções, ajudando-o, pois, a conhecê-lo melhor. (ZILBERMAN, 1985, p. 22).

E qual é o papel da escola nesse processo? Como a instituição pode influenciar na formação de alunos-leitores críticos? Compreendemos que na atualidade o espaço da escola é fundamental para efetivar o acesso de muitos jovens às obras literárias. De acordo com a $3^{a}$ edição da pesquisa "Retratos da Leitura no Brasil", ${ }^{2}$ realizada pelo Instituto Pró-Livro em 2011, entre os jovens de 11 a 13 anos, 47\% afirmaram que sua principal forma de acesso a livros é por meio da biblioteca escolar. Entre os jovens de 14 a 17 anos esse número é ainda maior: 48\% deles tem na escola a referência principal para acesso a livros. Outra questão relevante é o papel dos professores como fomentadores da prática da leitura. Ainda de acordo com a pesquisa citada, em 2011, ao responderem a seguinte pergunta: "Qual é a pessoa que mais influenciou ou incentivou o seu gosto pela leitura?" $45 \%$ dos entrevistados responderam que foram seus professores.

\footnotetext{
2 Pesquisa com amostra de 5012 entrevistas, realizada em 315 municípios de todos os estados e distritos brasileiros. Disponível em: <http://prolivro.org.br/home/>. Acesso em: 20 set. 2015.
} 
Reconhecemos, dessa forma, o importante papel assumido pela escola e pelos professores no incentivo à prática da leitura no contexto atual e concordamos, portanto, com Costa (2007, p. 10), que "[...] cabe à escola promover o crescimento do leitor, seja pelo contato com muitos e variados temas de leitura, seja quanto ao formato da escrita literária, seja, ainda, pelo compartilhamento e pela discussão de ideias com o uso de argumentação sólida e coerente".

A justificativa que legitima o uso do livro na escola nasce, de um lado, da relação que estabelece com seu leitor, convertendo-o num ser crítico perante sua circunstância; e, de outro, do papel transformador que pode exercer dentro do ensino, trazendo-o para a realidade do estudante e não submetendo este último a um ambiente rarefeito do qual foi suprimida toda a referência concreta. (ZILBERMAN, 1985, p. 26).

No entanto, é importante destacar que a prática de leitura na escola, ou incentivada por esse meio, deve ser realizada com a mediação dos professores. É consenso entre pesquisadores e estudiosos que o trabalho com obras literárias deve ser intermediado por profissionais, não apenas encaminhando os conteúdos e as possíveis aprendizagens desse processo, mas também evidenciando aos alunos o prazer da leitura e as sensibilidades que envolvem tal atividade. (COSTA, 2007, p. 20).

De forma geral, existe uma grande distância entre o discurso sobre a importância da leitura e sua prática. As nossas bibliotecas escolares muitas vezes servem como lugar de castigo, para serviços de utilidade escolar e guarda-volumes, mas raramente são um espaço de fruição da leitura, de dinamização e consolidação da prática leitora como prazer e emancipação. Estou certa de que nossas crianças gostam, sim, de ler [...]. O que Ihes falta, muitas vezes, é o estímulo, é o acesso a um material mais literário e menos didático. (BRETAS, 2012, p. 63).

Nesse sentido, questionamos: quais professores devem ser responsáveis pela "tarefa" de incentivar a leitura nos jovens? De acordo com Bretas (2012) nos últimos anos, a responsabilidade de formar alunos-leitores tem sido exigida em grande parte apenas daqueles professores dos anos iniciais do Ensino Fundamental e daqueles especializados em Literatura ou 
Língua Portuguesa. Contudo, sabe-se que "aprender a ler" deve ser uma discussão que permeie todos os campos do saber.

Ainda existe na comunidade escolar a cultura de que a formação do aluno leitor é de responsabilidade dos professores das séries iniciais e de Língua Portuguesa e Literatura, quando, na realidade, os níveis e os processos de leitura não caminham em uma só direção, nem para uma só área do saber. (BRETAS, 2012, p. 25).

\section{As possibilidades de articulação com o ensino de história}

Assim, reconhecemos que faz parte da disciplina de história contribuir para a formação do leitor crítico, capaz de interpretar textos literários e articulá-los de forma coerente com o campo do saber histórico. Portanto, compreendemos que o procedimento de leitura é muito mais do que realizar uma eficiente decodificação da linguagem de um texto: é compreender seu contexto, relacioná-lo com seu cotidiano, criticá-lo segundo métodos definidos e, até mesmo, surpreender-se com suas possibilidades.

Como não usar a literatura infantil como meros complementos ou ilustração? Acreditamos que a literatura infantil constitui uma fonte extremamente rica a ser problematizada pelo professor, que, por meio de um trabalho interdisciplinar, promoverá o acesso do aluno a outras linguagens, outras histórias, e o desenvolvimento de posturas críticas e criativas. Acreditamos que podemos enriquecer 0 processo de alfabetização e ampliar a aprendizagem histórica num processo de diálogo, aberto, livre e sensível entre memória, tempo, história. (ZAMBONI; FONSECA, 2010, p. 351).

Ao buscarmos essa perspectiva que insere a literatura infantil/juvenil como uma possibilidade ao professor de história, deve-se atentar para que não seja realizada uma escolarização inadequada desse tipo de material. 0 conceito de escolarização da literatura é definido quando a escola e seus representantes, no caso os professores, se apropriam de materiais literários pedagogizando-os e utilizando-os para determinados fins.

Deve-se primar que esse trabalho em sala de aula seja feito por meio de um diálogo aberto e livre com o material literário, para que essa 
escolarização seja feita de maneira adequada. Segundo Soares (2006), a forma mais eficiente de se realizar esse procedimento de escolarização da literatura é aproximar a leitura ocorrida na escola daquela realizada costumeiramente no contexto social de vida do aluno. Assim, são rejeitadas propostas de atividades que engessem o procedimento de leitura, estabelecendo normas e questões pré-concebidas a serem respondidas pelos alunos como mera abordagem superficial e como um "excesso de didatismo e burocracia". Afinal, o que se busca é o leitor "[...] capaz de se safar até mesmo das camisas de força impostas pela escola e pela sociedade, na medida em que produz sentidos que fogem ao controle inerente à leitura e à sua metodologia." (WALTY, 2006, p. 52).

Para que se tenha clareza sobre a abordagem mais adequada de utilização desses materiais e para que se perceba as possibilidades da literatura infantil/juvenil no processo de aprendizagem histórica, devemos primeiramente nos atentar para a definição desse conceito. Sobre qual aprendizagem histórica estamos falando? Segundo Rüsen (2011a), aprender é um processo dinâmico, que transforma internamente a pessoa do aprendiz. Assim, "[...] algo é ganho, algo é adquirido - conhecimento, habilidade ou uma mistura de ambos" (RÜSEN, 2011a, p. 82). Para esse autor, quando o conhecimento histórico passa a desempenhar um papel na constituição mental do sujeito é que se constitui o processo de aprendizagem. Fatos, ações e concepções sobre o passado, quando apreendidas pelo sujeito passam a interagir com seu modo de pensar e tornam-se um "assunto do conhecimento consciente".

A aprendizagem em história requer, portanto, um processo de internalização de "[...] conteúdos e categorias históricas viabilizadores de processos de subjetivação, isto é, de interiorização com intervenção dos sujeitos, com vistas às ações transformadoras da realidade" (SCHMIDT, 2009, p. 34). Verifica-se, dessa maneira, o desenvolvimento da consciência histórica, que permite que os alunos expressem sua compreensão sobre o passado e construam sua orientação temporal de forma historicamente fundada (SCHMIDT, BARCA, GARCIA, 2011). Dessa forma, 
[...] espera-se que o aparato conceitual da história habilite os jovens a desenvolverem [...] as suas interpretações do mundo humano e social, permitindo-Ihes, assim, melhor se situarem no seu tempo. A consciência histórica será algo que ocorre quando a informação inerte, progressivamente interiorizada, torna-se parte da ferramenta mental do sujeito e é utilizada, com alguma consistência, como orientação no quotidiano. (SCHMIDT, BARCA, GARCIA, 2011, p. 16).

Concordamos com Rüsen (2011b), portanto, que o ensino de história não deve se mostrar como uma "mera absorção de um bloco de conhecimentos", mas sim como um processo onde se estabelece perguntas e respostas, interpretações, e se fundamenta um conjunto de operações mentais capazes de orientar na vida prática e na formação identitária dos sujeitos.

$\mathrm{Na}$ atualidade defende-se, pois, que a aprendizagem é um processo de permanente construção. A aprendizagem constitui, assim, um processo ativo no qual o aluno compara, expande, restaura e interpreta o conhecimento, recorrendo à experiência e à informação que a todo momento recebe. (GAGO, 2012, p. 24).

A estreita ligação entre o conhecimento histórico e a vida prática do indivíduo é um tema recorrente nas discussões de Rüsen. Segundo a concepção desse autor, o conhecimento histórico representa "[...] uma resposta cultural ao desafio decorrente do fato de que os seres humanos vivem no fluxo do tempo, em meio a circunstâncias que não podem determinar por completo" (ASSIS, 2010, p. 17).

Dentro desse contexto, verificamos que é bastante amplo o conjunto de obras que apresenta a potencialidade de ser abordado na aprendizagem histórica, configurando-se como materiais paradidáticos. No entanto, uma nova tendência em particular do mercado literário brasileiro é digna de maior atenção pelos historiadores: as narrativas envolvendo aspectos relacionados aos indígenas e aos africanos. Coelho (2010) aponta que a maioria dessas obras se configura como uma "busca/afirmação da identidade cultural brasílica". Para a autora,

Ainda na esfera da 'literatura híbrida', destacamos duas correntes que dia a dia vêm crescendo em valor literário e importância histórica. Ambas vêm 'escavando' nossas origens 
de povo: a corrente das narrativas indígenas e a das narrativas africanas. De maneira comovente ou divertida ou fantástica, as histórias/estórias recuperadas/reinventadas de um passado remoto vão revelando aos pequenos leitores peculiaridades de dois povos, tão diferentes entre si e que, por artes do destino (ou de Portugal?), acabaram fazendo parte das raízes da nossa brasilidade. (COELHO, 2010, p. 291).

Principalmente a partir do início do século $X X I$, as iniciativas educacionais que trazem ao debate os povos africanos e os afrodescendentes brasileiros vêm ganhando força nos debates acadêmicos e nas mídias. A isso se deve, em grande parte, o estímulo proporcionado pela Lei 10639/03, que institui o "ensino sobre História e Cultura Afro-Brasileira" nos currículos.

A promulgação da Lei 10639/03 trouxe para o cenário da educação formal fatos, dados e conceitos até então não discutidos, sob a ótica da cultura hegemônica, pois, qualquer outra manifestação cultural era, tendenciosamente, identificada como periférica, marginal, dentre outras adjetivações, todas essas compreendidas como subalternas. (SILVA, 2012, p. 40).

Os paradidáticos voltados aos temas da história da África e da cultura afro-brasileira constituem, portanto, uma das mais recentes tendências do campo literário e apresentam-se como um possível recurso à discussão identitária nas aulas de história. Como vimos anteriormente, a literatura proporciona o alcance a realidades distintas, o contato com o outro, em contextos sociais diversos e por meio de narrativas que estimulam a empatia. Tais discussões são fundamentais no contexto escolar e integram o campo do conhecimento histórico.

Segundo Rüsen (2014), a identidade é o resultado de um procedimento mental, de orientação interna, no qual nos definimos em relação ao outro e em relação à natureza. Nas palavras do autor, é a "maneira como as pessoas se referem a si mesmas". Consideramos tal discussão como necessária no processo de aprendizagem histórica, principalmente porque

$\mathrm{Na}$ era da globalização, crescem as redes comunicativas e, ao mesmo tempo, os potenciais de agressão oculto nos encontros, nas sobreposições e mesclas de tradições, pertenças e delimitações culturais. Ao mesmo tempo aumenta também a necessidade de lançar um olhar retrospectivo sobre a história da própria cultura, para avaliar as possibilidades e 
os limites do entendimento intercultural e explorar os potenciais das ações de reconhecimento mútuo em face da alteridade e da diferença. (RÜSEN, 2014, p. 17, 18).

\section{Considerações finais}

Considerando as reflexões expostas acima, sabe-se hoje que as pesquisas que buscam investigar os livros paradidáticos voltados ao ensino de história ainda são escassas no Brasil. Prioritariamente, costuma-se estudar os livros didáticos (BITTENCOURT, 2008, p. 303), suas narrativas, a forma como estão dispostos os conceitos, como esses livros didáticos são aplicados e compreendidos por professores, de que forma os alunos assimilam as ideias que estão ali apresentadas, etc. No entanto, como foi visto anteriormente, nas últimas décadas sabemos que as escolas e os alunos têm adquirido acesso a materiais cada vez mais diversificados. Além disso, o processo de escolha e de utilização dos diversos materiais didáticos disponíveis é uma questão política, pois envolve diretamente o comprometimento dos professores com a formação dos alunos.

Assim, consideramos que "a escolha dos materiais depende, portanto, de nossas concepções sobre o conhecimento, de como o aluno vai apreendêlo e do tipo de formação que estamos oferecendo" (BITTENCOURT, 2008, p. 299). Dessa forma, evidencia-se a importância das reflexões acerca dos tipos de materiais que têm sido utilizados em sala de aula e suas relações com um ensino de história significativo.

\section{Referências}

ASSIS, A. A teoria da história de Jörn Rüsen: uma introdução. Goiânia: Editora UFG, 2010.

BITTENCOURT, C. M. F. Ensino de história: fundamentos e métodos. 2 ed. São Paulo: Cortez, 2008. (Docência em formação).

BRETAS, M. L. B. Leitura é fundamental: desafios na formação de jovens leitores. Belo Horizonte: RHJ, 2012. 
COELHO, N. N. Literatura infantil: teoria, análise, didática. São Paulo: Moderna, 2000.

N. N. Panorama histórico da literatura infantil/juvenil: das origens indo-europeias ao Brasil contemporâneo. 5. ed. Barueri (SP): Manole, 2010.

COSTA, M. M. da. Metodologia do ensino da Literatura Infantil. Curitiba: Ibpex, 2007.

DECERTEAU, Michel. A invenção do cotidiano. 3. ed. Trad. Ephraim Ferreiras Alves. Petrópolis: Vozes, 1998.

FONSECA, S. G. Didática e prática de ensino de história: experiências, reflexões e aprendizados. Campinas: Papirus, 2003. (Coleção magistério: Formação e trabalho pedagógico).

GAGO, M. Pluralidade de olhares: construtivismo e multiperspectiva no processo de aprendizagem. Moçambique, EPM/CELP, 2012.

GATTI JUNIOR, D. A escrita escolar da História: livro didático e ensino no Brasil (1970-1990). Bauru (SP): Edusp, 2004. (Coleção Educar).

LAGUNA, A. G. J. A contribuição do livro paradidático na formação do alunoleitor. Augusto Guzzo Revista Acadêmica, São Paulo, n.2, 2001. Disponível em: <www.fics.edu.br/index.php/augusto_guzzo/article/view/81>. Acesso em: 14 ago. 2015.

RÜSEN, J. Experiência, interpretação, orientação: as três dimensões da aprendizagem histórica. In: SCHMIDT, M. A.; BARCA, I.; MARTINS, E. R. (Org.). Jörn Rüsen e o ensino de história. Curitiba: Ed. UFPR, 2011a. p. 7992.

Aprendizado histórico. In: SCHMIDT, M. A.; BARCA, I.; MARTINS, E. R. (Org.). Jörn Rüsen e o ensino de história. Curitiba: Ed. UFPR, 2011b. p. 41-50.

. Cultura faz sentido: orientações entre o ontem e o amanhã. Trad. Nélio Schneider. Petrópolis: Vozes, 2014.

SCHMIDT, M. A. Cognição histórica situada: Que aprendizagem histórica é esta? In: SCHMIDT, M. A.; BARCA, I. (Org.) Aprender história: perspectivas da educação histórica. Ijuí: Ed. Unijuí, 2009. (Coleção Cultura, escola e ensino). p. 21-51.

; BARCA, I.; GARCIA, T. B. Significados do pensamento de Jörn Rüsen para investigações na área da educação histórica. In: SCHMIDT, M. A.; BARCA, Isabel; MARTINS, E. R. (Org.). Jörn Rüsen e o ensino de história. Curitiba: Ed. UFPR, 2011. p. 11-21. 
SILVA, S. M. da. Literatura Negra Brasileira: leitura e escrita. In: GONÇALVES, M. A. R.; RIBEIRO, A. P. A. (Org.). História e Cultura Africana e Afro-brasileira na Escola; Rio de Janeiro: Outras Letras, 2012.

SOARES, Magda. A escolarização da literatura infantil e juvenil. In: EVANGELISTA, Aracy Alves Martins; BRANDÃO, Heliana Maria Brina; MACHADO, M. Z. V. (Org.). Escolarização da leitura literária. 2. ed. Belo Horizonte: Autêntica, 2006. (Linguagem e educação).

WALTY, I. L. C. Literatura e escola: anti-lições. In: EVANGELISTA, A. A. M.; BRANDÃO, H. M. B.; MACHADO, M. Z. V. (Org.). Escolarização da leitura literária. 2 ed. Belo Horizonte: Autêntica, 2006. (Linguagem e educação).

ZAMBONI, E. Que História é essa? Uma proposta analítica dos livros paradidáticos de história. Tese (Doutorado em Educação) - Universidade Estadual de Campinas, Campinas, 1991.

E.; FONSECA, S. G. Contribuições da literatura infantil para a Aprendizagem de noções do tempo histórico: Leituras e indagações. Cad. Cedes, Campinas, v. 30, n. 82, p. 339-353, set.-dez. 2010. Disponível em: <http://www.cedes.unicamp.br>. Acesso em: 1 de setembro 2015.

ZILBERMAN, R. A literatura infantil na escola. 4 ed. São Paulo: Global, 1985. 